\title{
19. Fandom Edits
}

\author{
Rogue One and the New Star Wars
}

\author{
Gerry Canavan
}

For the first 35 years of its existence, the Star Wars franchise was branded as the inspired vision of a single auteur-genius, George Lucas, who controlled the franchise both creatively and economically. Among its major competitors in science fiction and fantasy, perhaps only Tolkien's The Lord of the Rings has been so closely identified with the mind of one person-and where Tolkien had his legendarium, the mythopoeic totality of the Middleearth narrative, Lucas had his saga. In interviews, Lucas typically spoke of the Star Wars saga as a unitary megatext from which the first movie just happened to draw somewhere in the middle. ${ }^{1}$ Lucas's self-conscious promotion of Star Wars as a modern myth-intensified by his frequent references to Joseph Campbell's study of mythic narrative, The Hero with a Thousand Faces - presented the narrative as emerging from a coherent "master plan" Lucas developed in the 1970s and that has slowly unfurled ever since. Borrowing from Foucault the concept of the episteme-that "strategic apparatus" within a discourse that allows "a field of scientificity" to determine what is thinkable and unthinkable within that system ${ }^{2}$-we might say that Star Wars had, until recently, treated Lucas's authorial vision as the "one episteme that defines the conditions of possibility of all knowledge." In this chapter, I discuss Rogue One in the context of the 2012 sale of the Star Wars franchise to Disney, which functions as a moment of epistemic break for the Star Wars franchise. While Star Wars remains Star Wars both before and after this moment, our relationship to it as a system of knowledge is entirely different; indeed, in this strange early moment of transition between one episteme and the next, we might even say the current Star Wars episteme finds itself in a period of civil war.

1 Both the Tolkien legendarium and the Star Wars saga share this sort of bleed between text and archival paratext as well; in both cases, much of the "full story" exists only in interviews, letters, and author's notes, to the extent that it exists in any fixed form at all.

2 Michel Foucault, Power/Knowledge: Selected Interviews and Other Writings, 1972-1977 (New York: Pantheon Books, 1980), 197.

3 Michel Foucault, The Order of Things: An Archaeology of the Human Sciences (New York: Vintage Books, 1994), 168. 


\section{Lucasfilm Minus Lucas}

Either as corporate brand or as episteme, any proposed coequality between Lucas and the franchise already ignores key elements of the franchise's development since 1977. First, it brackets Lucas's own frequent changes and reformations of what the terms of that supposed master plan originally entailed. It likewise diminishes the importance of Lucas's many creative collaborators on the original trilogy, including editor Marcia Lucas (his ex-wife), screenwriters Lawrence Kasdan and Leigh Brackett, and directors Irvin Kershner and Richard Marquand, whose contributions to the Star Wars saga were recoded as marginal or incidental within the logic of the mythopoeic saga episteme.

That idea of Star Wars as a saga authored by a single creative genius becomes even more untenable when considering the EU of transmedia expansions. I am hardly the first to note that Star Wars only properly became science fiction, as opposed to space fantasy or even space fairy tale, within the more nuanced EU material, which took the comparatively juvenile films as building blocks to sketch out a larger and much more complicated galactic world-system. ${ }^{4}$ In interviews, Lucas himself has always recognized the existence of these competing EU texts as a genuine challenge to his narrative authority, albeit one he did not ultimately accept:

Starlog: The Star Wars Universe is so large and diverse. Do you ever find yourself confused by the subsidiary material that's in the novels, comics, and other offshoots?

Lucas: I don't read that stuff. I haven't read any of the novels. I don't know anything about that world. That's a different world than my world. But I do try to keep it consistent. The way I do it now is they have a Star Wars Encyclopedia. So if I come up with a name or something else, I look it up and see if it has already been used. When I said [other people] could make their own Star Wars stories, we decided that, like Star Trek, we would have two universes: My universe and then this other one. They try to make their universe as consistent with mine as possible, but obviously they get enthusiastic and want to go off in other directions. ${ }^{5}$ 
With the eventual release of the special editions and mixed critical reception of the prequels, the authority of Lucas's vision began to face an even more dangerous challenge: the rebellion of the saga's most-devoted fans. A cottage industry of post- and anti-Lucas reconceptualizations of the Star Wars franchise emerged: bootleg "despecialized" editions of the original trilogy that remove Lucas's changes have circulated on the internet as the "proper" way to view the film, as have various edits of the prequels that remove their supposedly problematic content (including the so-called Phantom Edit, cutting eighteen minutes of The Phantom Menace) and actor Topher Grace's re-edit of the prequels into a single 85 -minute feature. The widely circulated Machete Order fan practice does The Phantom Edit one better, proposing that future viewers ought to ignore Lucas's pretensions to mythopoeic unity and screen the films in the order IV, V, II, III, VI, VII (omitting I entirely). ${ }^{6}$ Circulating mostly via memes and forum posts, the now well-known Darth Jar Jar theory_-which attempts to make sense of the unhappy foregrounding and subsequent unceremonious backbenching of the controversial CGI character by proposing that he is actually the secret evil mastermind behind the rise of the Empire-is only the most popular of a large number of fan rewrites, reconceptualizations, and "head canons" that have sought to improve the prequels. ${ }^{7}$ Most widespread among fans, though, is the ultimate fan edit: a running joke wherein fans of the franchise collectively agree to pretend among themselves that the prequels never happened. ${ }^{8}$

Still, it cannot be denied that Lucas provided the epistemological grounding for Star Wars in the first decades of its existence. In its so-called Jedi Holocron, a database containing tens of thousands of entries detailing all known persons, places, technologies, and events within the Star Wars universe, Lucasfilm developed an internal hierarchy of knowledge—eventually adopted by fans as well— that formally prioritized the original films and proclamations of Lucas, followed by various devalued levels of secondary canon. With the sale to Disney in 2012 and Lucas's formal removal as the creative figurehead of the Star Wars project, a sort of epistemic crisis has emerged for the franchise. Now the saga has continued into a new trilogy

6 Rogue One, discussed below, poses an interesting problem for the Machete Order viewer. Should Rogue One, as "Episode 3.5," be watched before A New Hope? After? After The Force Awakens? Should it be watched at all?

7 DarthJarJar, accessed May 15, 2017, http://darthjarjar.com.

8 In parallel, many older fans of the franchise have become prickly even on the question of the proper name for the original Star Wars film, many now refusing the A New Hope retitling as a gesture that refuses Lucas's authority as sovereign (re-)writer. 
without Lucas's supposedly unitary vision and also expanded into the anthology films that will tell new stories that likewise fall outside the scope of Lucas's mythopoeia. These films will be accompanied by a new set of transmedia tie-ins, replacing the old EU, which has been relegated to the status of Star Wars Legends. With this new, clean slate, Disney's plan is for transmedia licensed works such as comics, books, toys, and video games to be henceforth developed in tight internal consistency, eliminating any need for internal divisions of canon. In the post-Lucas Star Wars there will thus be more and more texts competing for the top level of authority, as well as more writers, directors, set designers, costumers, tie-in novelists and comics artists, toy designers, corporate hacks, etc. all speaking with equal authority about Star Wars - none of whom possess the same sort of obvious sovereignty over the franchise once held by Lucas and the original films.

Disney's ambitious multi-decade plans for the anthology films- "You Won't Live to See the Final Star Wars Movie," as Wired memorably put it - will soon swamp the Lucas-inspired saga films centered on the drama of the Skywalker family, ostensibly in favor of a larger Star Wars universe in which other sorts of stories about other sorts of characters might be told. Of course, given the extremely poor reception of the prequels, the decentering of Lucas has generally been taken as good news for the health of the franchise. Still, the external shift in the political economy of the Star Wars franchise takes on a challenging epistemological character with regard to the internal continuity of the shared universe. Where once the process of adjudicating the canonicity of a given fact was in some sense automatic —is it in the movies? did George say it?-it now requires more complex considerations among a much larger series of competing texts and authors that will inevitably come into conflict with one another.

What's more, without even the fiction of a Lucas-authored master plan licensing its creative ambition, Disney cannot help but admit that they are simply making things up as they go along, thereby weakening fan confidence that the sequel trilogy and post-saga anthology material will ultimately cohere to the extent the original trilogy did. J.J. Abrams famously announced in interviews around the release of The Force Awakens that he did not work on the next two episodes at all, saying he was leaving them in the capable hands of Rian Johnson (who announced in interviews that he did not work on the untitled Episode IX). All the Disney-era saga films have had extensive periods of rewriting and reshooting, sometimes leading to significant delays in production, as with the six-month delay in the release of The Last Jedi and the shock firing of directors Phil Lord and Chris Miller from Han Solo in favor of Ron Howard midway through production. Disney 
has also conceded that, following the unexpected death of Carrie Fisher in December 2016, it has simply had to "start over" with Episode IX entirely. ${ }^{9}$ These twists and turns are strongly at odds with the more mythopoeic idea of Star Wars. Furthermore, Disney cannot help but fuel fan speculation about the contingencies and competing creative visions that influence a finished product, as well as further encourage fans to create their own competing canons and visions for the franchise. In what follows, I propose that Rogue One offers an opportunity for us to check in on the formation of this new, unmoored episteme of the Star Wars franchise in the moment that it is still taking shape; for the moment, after all, Rogue One is still the rogue one-the outlying exception that will soon become the rule.

\section{Rogue One: Defining the Anthology Film}

As soon as Rogue One was announced, it began to fuel speculation as to what a non-saga Star Wars film would look like. Would it begin with the familiar fanfare and opening crawl? Would there be the familiar early shot of a starfield, quickly panning away to a spaceship? Would it use the wipes between scenes that the classic and prequel movies did? Would it use music from the original trilogy? Would it use a John Williams-style orchestral score at all? Questions like these drive home the unusual nature of the anthology film project for the franchise by questioning what formal elements - what sights, sounds, paratexts, editing techniques—stamp a movie as truly a Star Wars film. Interviews with the production crew have made clear that formalist concerns around familial resemblance strongly occupied the studio during Rogue One's production, at times swinging back and forth between possibilities. Fans likewise hotly debated the possibilities among themselves as they waited for news to trickle out. This period of anticipation set the pattern that emerged across Rogue One's production and reception: Disney's lack of sovereign control over the Star Wars episteme necessarily produces competing visions among fans who not only understand themselves more as co-creators than as passive receivers of the franchise, but who now possess the digital tools to easily create and distribute their own alternative visions of the franchise.

9 Esther Zuckerman, “Disney Started over on Star Wars: Episode IX after Carrie Fisher's Death," The A.V. Club, May 5, 2017, accessed May 15, 2017, http://www.avclub.com/article/ disney-started-over-star-wars-episode-ix-after-car-254835. 
In the end, Rogue One distanced itself formalistically from the Star Wars saga in a number of key ways: there is no opening fanfare or crawl, in favor of a cold open, and the film uses regular cuts as opposed to Lucas's famous wipes to move between scenes. The film also adds non-diegetic onscreen text to indicate on which planet each scene takes place, a new technique for the franchise. At the same time that it attempts to assert these kinds of minor formal differences, however, Rogue One takes pains to inject itself into the continuity of the original films, even to an extent that some might describe as painful, suturing itself to the old Star Wars saga even as it begins the process of ostensibly expanding and remaking it. The film draws its plot from the furst line of the original opening crawl of ANew Hope- "Rebel fighters, striking from a hidden base, have won their first victory over the evil Galactic Empire" - and contains frequent narrative and visual references to that movie, even ending on a CGI shot of the young Princess Leia set perhaps minutes before the first film begins. The film lovingly recreates that milieu in costumes, staging, and visual composition, even deploying previously unused footage of X-wing pilots from A New Hope to link the two films' background characters together (as well as including obtrusive cameos from R2-D2, C-3PO, Darth Vader, the two troublemakers from the Mos Eisley Cantina, and so on).

The flip side of this strict (even suffocating) devotion to the original Star Wars canon is that Rogue One presents itself as utterly disposable from the perspective of the Star Wars saga. Because every major character dies and every plot thread flows directly into A New Hope, without any excess, the film presents itself as emphatically optional from the perspective of the larger saga. Early fan assumptions that there would someday be a Rogue Two, or that characters from Rogue One would eventually appear in the saga films - based in part upon rumors that Felicity Jones had been contracted for at least two movies-proved unfounded; instead, Rogue One neatly dismantles itself, leaving behind no residue or storyworld mess. Marketed as the untold story behind the destruction of the Death Star, the film leaves the viewer with the impression that the story is untold within the Star Wars universe itself. Despite the direct participation of many of the principals from the original trilogy, none of its events are ever mentioned by the saga characters again, even in their immediate aftermath. Rogue One's commitment to its own self-sterilization in the service of canon hygiene is truly profound.

Contrary to the supposed expansion of the universe effected by the anthology films, then, Rogue One actually grants the saga films maximum priority. As more anthology films arrive, this paradox will only intensify, 
eventually making the original totalized view of a mythic saga untenable while simultaneously reinforcing the importance of the saga films as the only possible common ground among a decentered and multiply authored megatext. Moreover, without the imprimatur of an acknowledged auteur granting it textual authority within the Star Wars episteme, Rogue One seems unable to sustain a single canonical interpretation even within its own limited terms. In practice, Rogue One has been marketed with a strategy that is nearly the opposite of the one used by the original Star Wars saga; that is, rather than adopting the pose of a singular mythopoeic vision, springing into existence fully formed, in its marketing for Rogue One, Disney instead highlighted Rogue One's multi-author and highly contingent design process, including its rewritings, reshoots, excisions, and apocrypha. Where the original mode of Star Wars fandom was a kind of exegesis - unpacking a divine myth that came to us from on high, or from our collective unconscious, by way of Lucas's artistic vision-the new mode of Star Wars reception is instead a collaborative and negotiated co-creation, in which the fan is invited by the creators themselves to rewrite the movie and its place in the larger mythos in whatever terms they prefer.

The initial spark for fandom edits-and their unusual promotion by Disney - apparently occurred only by accident. The first teaser trailer for Rogue One was released on April 7, 2016 and featured a number of striking moments that never appear in the finished film; highly publicized reshoots later in the summer, as well as post-release interviews from the creative staff, indicate that the film was not yet in fixed form. After the film was released, the highly scrutinized trailer became the locus for investigation into that phantom originary version of the story. Fan news sites immediately produced lists of the major changes from the trailer to the finished film in an effort to produce a sense of what had been changed and to speculate about what the reasons might have been. The key change seems to be in the character of Jyn Erso (Felicity Jones), whose personality was evidently more hard-edged in the original vision of the film. The trailer presents her as something of a scoundrel (perhaps even a female variation on Han Solo) who has been drawn into the rebellion against type. A stern voice lists her rap sheet- "Forgery of imperial documents. Possession of stolen property. Aggravated assault. Resisting arrest" — while Mon Mothma talks about how reckless and undisciplined she is. Over scenes of violence, Erso retorts: "This is a rebellion, isn't it? I rebel." The trailer ends on a shot of Jyn in a TIE Fighter pilot's uniform under dialogue asking "What will you become?" further suggesting that the character will be in some sense fundamentally 
untrustworthy, even perhaps that she might ultimately betray the Rebellion, or at least appear to do so.

The seeds that were planted here influenced interpretation of the later trailers, snowballing into a premediation of the film centered on Jyn that was strongly at odds with the finished film. Consequently, initial fan reception of the film returned to the trailer (especially the initial teaser) to discover that most of what was presented in that format was cut, including its most memorable images and dialogue. Jyn's character is not, as the trailers made it appear, a dangerous criminal brought in by a desperate Rebellion to do a dirty job; she is instead recruited to be a living letter of introduction that gains the Rebellion access to characters they might otherwise not be able to speak to. Likewise, nearly all of the dialogue portraying her as an anti-hero was gone, as was most of her roguish edge; or, as K.M. McFarland's analysis put it, "somewhere along the way Jyn-as-agitator got downgraded to Jyn-asjaded-neutral-objector. ${ }^{10}$ Without the fan expectations produced by the premediation of the trailers, Erso's personal motivations and backstory are fairly opaque, and her character therefore largely remains a cipher. Perhaps not incidentally, much of the initial fan analysis of the film has found itself nostalgic for the trailer, as opposed to appreciating the finished film - more attached to the premediation than to the thing itself.

The film's bleak ending similarly turns out to have multiple possibilities in the trailers, with characters appearing in locations during the final heist that would be impossible in the narrative as presented. In this difference between the trailer and the final film, the development of a new episteme in Star Wars is clear; while the facts of Rogue One are set (they all die), the explanation for the emergence of that set of facts becomes a contested site of speculation between text, paratext, creators, and fans. Who intervened, when, and why, to give us this Rogue One - as opposed to any one of its many possible alternatives? In the old Star Wars we could have simply said, for better or worse, "George did it"; in contrast, the new Star Wars produces multiple competing actors, each exerting force on the production, with no one faction definitively responsible for any one creative choice, or even appearing to have final authority.

Perhaps sensing this muted sense of fan dissatisfaction, Disney's postrelease strategy has focused to an unusual extent on explaining how the film reached its finished form, as well as detailing other directions the

10 K.M. McFarland, "Let's Take a Second to Think about the Rogue One That Almost Was," Wired, December 20, 2016, accessed May 15, 2017, https://www.wired.com/2016/12/rogue-one -discarded-dialogue. 
narrative might have taken. A lengthy interview with editors John Gilroy and Colin Goudie at Yahoo UK walked fans through the process of the reshoots, ${ }^{11}$ while director Gareth Edwards's appearance on the podcast "The Director's Cut" explained his method of capturing material in a period of cinematic experimentation called an "Indie Hour": "It was just a way for the crew of understanding, for now, we're just going to do loads of random shit. Don't try to ask, we can't explain. It would just be things I thought were a beautiful moment or 'This is a great idea' and a lot of the stuff in the trailer ended up through that process." "Random shit"— quite a change from the mythic, quasi-divine inspiration that ostensibly birthed the Old Star Wars!

Other interviews with the Rogue One production staff further suggested the fraught process of conceptualizing the film even while it was being shot, including the last-minute addition of the climactic Darth Vader massacre at the very end of the film, which was added in at the last possible moment. The headline of a piece by Andrew Liptak at The Verge suggests the somewhat dangerous PR strategy here: "Rogue One's reshoots show how Disney saved the first standalone Star Wars movie." ${ }^{\text {"3 }}$ Rogue One was emphatically not, we are told, an inspired work of genius appearing fully formed within the mind of its creator; rather, it was nearly a disaster, something that had to be salvaged at the last minute. The inevitable implication is that other versions of the film might well have been better (or much worse) and that future entries in the franchise will likewise vary widely in planning, execution, tone, and overall quality. Unable to control the episteme of Star Wars with the authority Lucas once wielded and unable to microtarget global blockbusters to suit the interests and desires of every possible fan demographic, Disney's unique strategy with Rogue One has been to gesture to paratexts outside the final print and thereby invite Star Wars fans to remix and misremember the film in ways they find more pleasing. Very much by design, there is now many more than just one Rogue One.

The key exception to this marketing strategy has been in the DVD and Blu-Ray releases, which contain little deleted material despite its

11 Tom Butler, "Rogue One's Editors Reveal the Scenes Added in the Star Wars Standalone Reshoots (Exclusive)," Yahoo UK, January 3, 2017, accessed May 15, 2017, https://uk.movies. yahoo.com/rogue-ones-editors-reveal-scenes-added-in-the-star-wars-standalone-reshootsexclusive-110124381.html.

12 Qtd. in The Directors's Cut 52, https://soundcloud.com/thedirectorscut/episode-53-rogueone-a-star-wars-story-with-gareth-edwards-and-chris-miller.

13 Andrew Liptak, "Rogue One's reshoots show how Disney saved the first standalone Star Wars movie," The Verge, January 15, 2017, accessed May 15, 2017, https://www.theverge. com/2017/1/15/14268850/star-wars-rogue-one-reshoots-disney-gareth-edwards-tony-gilroy. 
importance to the film's post-release promotion. Disney has claimed, to fan frustration, that the material does not exist in sufficiently fixed form to be distributed as extras. "The stuff people talk about, like what they saw in the trailer, they're not scenes you can just put on a DVD," Gareth Edwards told Fandango in an interview.

They're moments within scenes and threads, and you pull a thread and it all changes. It was changing the whole time. It's not like there was one version and then there was this other version-it was like this thing that incrementally evolved constantly through all of post-production and didn't stop until there was a gun at our heads and we were forced to release the movie. ${ }^{14}$

Disney's marketing strategy for Rogue One thus rests on a core paradox: Rogue One exists in multiple forms for the purposes of fan identification and critical interpretation, while still only ever existing in a single fixed form.

The contradiction between Disney's proliferation of paratextual alternate versions of Rogue One - even above and beyond what it can actually commoditize as salable product, and outside the filmic canon the corporation will commit itself to respecting in future outings_-and its simultaneous insistence on the primacy of its final cut registers the final breakdown of the old Star Wars episteme. There, everything rotated around a core of movies - first three, then six — mythopoeically authored by George Lucas, on which the tie-in products commented but with which they did not really compete. If Rogue One is the model, the new Star Wars will be something quite different: now without a single privileged author and without any core text, every entry in the franchise will reproduce and intensify this tension between endlessly personalizable fan customization and flattened-out mass-audience appeal. In the anthology era, Disney will need to sell each Star Wars fan the version of each "Star Wars Story" they most prefer, all without taking the risk of alienating any other market or constraining the possibilities for maximum profit-seeking further down the line. Rogue One's middling success - fun enough, but formulaic, and instantly forgettable-suggests this will be a very difficult balancing act to pull off, much less iterate over and over again in a new Star Wars film every year for the rest of our lives.

14 Qtd. in Germain Lussier, “There's Something Weird About This Explanation for Why You Can't Watch Rogue One's Deleted Scenes," iog, March 14, 2017, accessed May 15, 2017, http://iog. gizmodo.com/theres-something-weird-about-this-explanation-for-why-y-1793264866. 


\section{The Keepers of the Whills}

Several years ago, Cory Doctorow made an interesting observation about fandom over the course of an email interview with one of my classes. Speaking about the "custodial" and intensively protective relationship that fans of Disney seem to have with the theme parks, Doctorow noted competing impulses within the Disney corporation. Over the years, the strategy has been to simultaneously inculcate this sort of fierce loyalty and to interrupt it, so that the "social contract" between fans and the corporation always "becomes a commercial relationship again," with The Disney Company's monetary interests indisputably at the head. For Doctorow, this tension recalled a plot from the 1992 Greg Egan novel Quarantine, in which people whose brains have been altered by a sinister conspiracy in order to ensure perfect loyalty ultimately overthrow the conspiracy's dark masters, on the grounds that only those with altered brains can be truly loyal to the conspiracy:

I always thought that was a really interesting little bit here, to say: who are you to say that you're the true keeper of the flame? Maybe I'm the true keeper of the flame. You're just a corporation who's in it to make as much money as you can from these assets. And maybe that converges sometimes with being the best custodian, and maybe sometimes it doesn't; maybe sometimes you'll go off and chase the quarterly profits at the expense of long-term value. Meanwhile, I have no commercial interest in it - therefore I'm a better custodian than you, I should have more say in it that you do. And I think that relationship beats in the heart of big Disney fans, the people you see who know the park like the back of their hand. ${ }^{15}$

In the context of Star Wars, of course, the more precise term would not be "flame" but "Whills." From his earliest drafts, Lucas imagined the Guardians of the Whills as a monastic order devoted to chronicling the history of the galaxy; he even described the Star Wars movies as a narrative told by R2-D2 to some "Keeper of the Whills" a hundred years or more after the events of the original trilogy. The Guardians of the Whills-long a saga paratext with canonical, Lucas-backed authority despite never appearing on

15 "Trying to Predict the Present: An Interview with Cory Doctorow," Gerry Canavan, Spring 2010, accessed May 15, 2017, http://gerrycanavan.wordpress.com/2015/04/08/from-the-archivesinterview-with-cory-doctorow-on-disney-sf-violence-meritocracy-goodharts-law-fandom-andutopia. 
screen-finally became canon in Rogue One in the characters Baze Malbus and Chirrut Imwe, non-Jedi who exhibit a religious devotion to the Force and even seem to have some access to its powers.

The reemergence of the Keeper of the Whills from the primordial Star Wars mythos into the post-Lucas Star Wars era provides an interesting figure for the task of managing the Star Wars episteme in its Disney era. The figure of the Keeper of the Whills suggests a history that is simultaneously authoritative and constructed-objective but perspectival, obsessively detailed but not total or complete. It foregrounds precisely the epistemic grounding that Star Wars now faces: a history that is neither authoritative nor authored but rather partial, polyvocal, and negotiated among multiple competing actors with sharply divided interests. ${ }^{16}$

It cannot be coincidence that, in the recent Aftermath: Empire's End novel, we see a glimpse of the holy writing of the Whills that points to the crisis of knowledge that comes to Star Wars after God (Lucas) is dead (or at least retired). Remixing the language from the foundational retcon of the Lucas era in Star Wars - the awkward moment in Return of the Jedi in which Obi-Wan comes close to conceding that everything he told Luke about his father in A New Hope was a lie - the Journal of the Whills proclaims: "The truth in our soul / Is that nothing is true. / The question of life / Is what then do we do? / The burden is ours / To penance, we hew. / The Force binds us all / From a certain point of view."17 The return to the Order of the Whills strikes me as a telling metaphor for the situation of Star Wars as a franchise in this moment of transformation: Disney has traded the epistemic certainty of the Lucas era for the post-authorial, post-mythopoeic multiplicity of the post-Lucas Star Wars. As an initial outing, Rogue One suggests this strategy will be financially lucrative, but creatively bankrupt — but this was only the Death Star's first test.

My thanks to Dan Hassler-Forest and the Rogue One panel at ICFA 2017 for help in developing these thoughts.

16 Leland Chee, developer of the original Lucasfilm continuity database, the Jedi Holocron, was dubbed "The Keeper of the Holocron" by Star Wars fans; fittingly, the Disney-era successor to the post (which includes Chee as one of many such "Keepers") is the somewhat less audaciously named “Lucasfilm Story Group," suggesting even more debate, disagreement, incompleteness, and uncertainty than even that provisional Keepership. The fan alternative is the collaborative, multi-authored Wookieepedia project.

17 Chuck Wendig, Star Wars: Aftermath: Empire's End (New York: Random House, 2017), 178. 